www.nature.com/pj

\title{
EDITORIAL
}

\section{Towards brighter futures for the Polymer Journal and polymer science}

Polymer Journal (2013) 45, 1; doi:10.1038/pj.2012.209

Cirst, I would like to take this opportunity to wish you all a Happy - New Year. Polymer Journal (PJ) commences its 45th volume in 2013 and this will be the fourth year of the publishing partnership between the Society of Polymer Science of Japan and Nature Publishing Group (NPG) for PJ. I feel very honored to have been appointed as the new Editor-in-Chief of PJ. I would like to thank Professor Toshikazu Takata, the former Editor-in-Chief, for his great contribution to the development of the journal and for instigating the publishing cooperation with NPG. ${ }^{1}$ It is apparent that as a result of this close collaboration, PJ has become more visible to the global audience. This is evident from the online access to the contents of PJ increasing significantly; please feel free to visit the website: http:// www.nature.com/pj/index.html. We will continue to work together to establish PJ as an essential resource and as an international platform for new results, new ideas and new concepts in polymer science and its related fields.

In 2012, the Society of Polymer Science, Japan (SPSJ), celebrated its 60th anniversary. During the year, we published three special issues: Ichiro Sakurada Special Issue, Vol. 44, No. 1; Self-Assembled Materials, Vol. 44, No. 6; and NMR of Polymers, Vol. 44, No. 8. All of these special issues attracted a great deal of attention within the community. For example, the Ichiro Sakurada Special Issue contains Memorial Papers, which are important in the history of polymer science. The cover pictures of these special issues are included below.

In 2013, we have planned two special issues: the current issue titled Application of Quantum Beams to Polymer Science and Engineering,
Vol. 45, No. 1 and Peptide Materials, Vol. 45, No. 5. I thank all of the guest editors for their hard work in organizing such excellent special issues.

However, PJ does not only publish excellent Special Issues, but also publishes excellent regular issues. PJ publishes Original Articles, Reviews, Focus Reviews, Notes, and Rapid Communications. In 2012, we started a new article type: the Focus Review, which focuses on an author's own contribution within a clearly defined area of research. In particular young investigators are welcome to submit Focus Review articles.

Finally, I would like to thank all the PJ authors, readers, referees and subscribers for their continued support of the journal. I would also like to thank the Editorial and Advisory Board members, the Associate Editors, the Guest Editors and the staff of editorial and production offices of SPSJ and NPG for their present and future contributions to PJ. Allow me to take this opportunity to invite submission of your next high-quality paper for publication in PJ, as we move together to advance the field of the polymer sciences.

Takashi Kato Editor-in-Chief, Polymer Journal, The University of Tokyo, Tokyo, Japan

1 Takata, T. Plans for 2012. Polym. J. 44, 1 (2012).
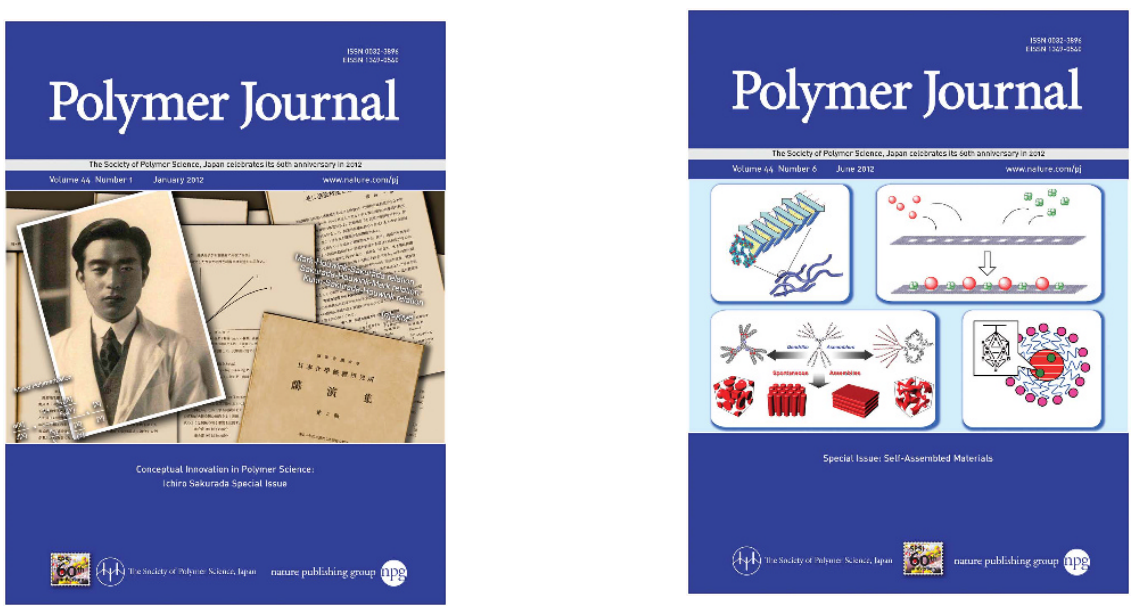
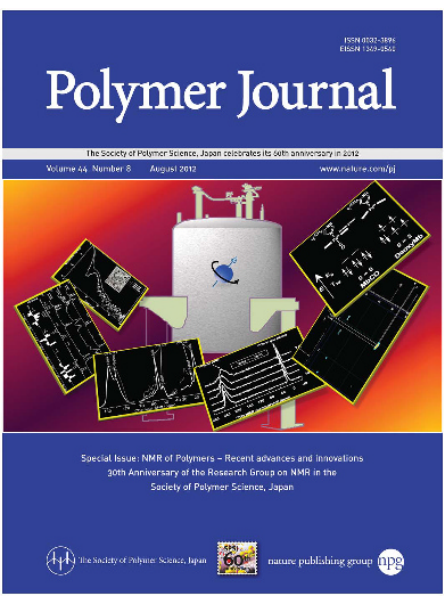